\section{Imaging features of ocular adnexal lymphoproliferative disease}

TJ Sullivan ${ }^{1,2}$ and AA Valenzuela

Tutivan 1,2 and AA

Abstract

Eye (2006) 20, 1189-1195. doi:10.1038/sj.eye.6702382

Purpose To evaluate the imaging characteristics of a cohort of patients with ocular adnexal lymphoproliferative disease (OALD).

Methods A noncomparative retrospective review between 1992 and 1995 and prospective study from 1995 to 2005 of the clinical, imaging and treatment of 105 patients presenting to tertiary orbital referral centre presenting with OALD.

Results One hundred and five patients (mean age 61 years, range 11-90 years) with equal gender distribution were included. Fifty-three were primary and 52 were secondary.

Computed tomography (CT) usually showed a well-circumscribed lesion of greater than brain density, moulding to adjacent tissues with moderate enhancement. Aggressive histology was associated with bone destruction, while moulding was associated with indolent histology $(P<0.005)$.

MRI in OALD showed intermediate signal intensity on T1- and T2-weighted images and moderate enhancement with gadolinium. Gallium scanning sensitivity to detect ocular adnexal disease was 25 and $57 \%$ for systemic involvement. Positron emission tomography (PET) upstaged $(\mathbf{7 1 \%})$ of patients with systemic lymphoproliferative involvement, having a higher sensitivity than $\mathrm{CT}$ in detecting distant disease (86 vs $72 \%$ ). Conclusions CT and/or MRI are essential in the evaluation of OALD and can be used to establish that an orbital lesion may be lymphoprolifetaive in nature. Further, these imaging modalities may predict the behaviour of the lymphoma in certain cases. Gallium scanning provides no additional information to CT and does not influence patient treatment. PET represents an important addition to the assessment of OALD with real impact on patient management.
Keywords: lymphoma; ocular adnexa; CT; MRI; PET; gallium

Introduction

The computed tomographic (CT) features of ocular adnexal lymphoproliferative disease (OALD) have been described in the past. ${ }^{1-6}$ Magnetic resonance imaging (MRI) studies have also been reported. ${ }^{5-7}$ However, the imaging features of ocular adnexal lymphoproliferative disease have not been well described with regards to recent advances in imaging techniques. Further, there is no current protocol for imaging studies in patients with this disorder. For this reason, we undertook a study to evaluate the imaging characteristics of a cohort of patients with OALD to propose a protocol for initial and ongoing imaging studies.

\section{Materials and methods}

One hundred and five cases of OALD were seen in a tertiary orbital referral centre from 1992 to 2005. Data from 1992 to 1995 were collected retrospectively in 1995, at which time a spreadsheet was developed to allow prospective information collection. Data were then collected prospectively from 1995 until 2005. Open surgical biopsy was performed to confirm the diagnosis in all cases.

Histomorphologic, immunophenotypic, and molecular genetic findings were used to establish the diagnosis. Flow cytometry, PCR, and cytogenetics generally confirmed the presumed histomorphological diagnosis and established evidence of monoclonality in some equivocal patients. Cases were classified according to the WHO modification of the REAL classification. ${ }^{8-10}$

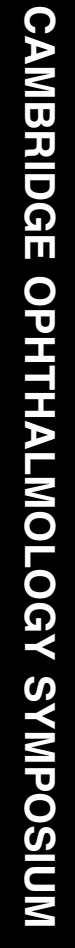

${ }^{1}$ Eyelid, Lacrimal and Orbital Clinic, Division of Ophthalmology, Department of Surgery, Royal Brisbane Hospital, Herston, Queensland 4029, Australia

${ }^{2}$ Department of Surgery, University of Queensland, Royal Brisbane Hospital, Queensland, Australia

Correspondence:

TJ Sullivan,

Tel: + 61738310101 ;

Fax: +61 738313203

E-mail: tjs@gil.com.au

Received: 12 March 2006 Accepted: 22 March 2006

Proprietary interest statement: The authors have no proprietary interests in any of the products mentioned in this paper

Meeting presentation: Presented in part at the 2005 Cambridge Ophthalmological Symposium, Cambridge, England, Sept 2005 
Anatomical site was divided into orbital, conjunctival, lacrimal sac, and eyelid lesions, based on clinical, imaging, and intra-operative findings, as previously defined. ${ }^{11}$ The CT scanning of the ocular adnexae was performed using axial and direct coronal 2-mm contiguous slice imaging, with administration of intravenous contrast. The images were evaluated by a single observer (TJS) for location, circumscription, density, enhancement with contrast media, moulding to adjacent structures, calcification, tissue invasion, and bone destruction. MRI characteristics studied included appearance on T1 and T2 weighted images in relation to the extra ocular muscles, as well as degree of enhancement with the paramagnetic substance gadolinium diethylene-triamine penta-acetic acid (gadolinium). The sensitivity of Gallium and Fluorine-18 fluorodeoxyglucose positron emission tomography (FDG-PET) scanning was also assessed for detection of both orbital and systemic disease at staging and compared to CT-scan. Patients were referred for systemic oncological workup and treatment planning. This included general clinical examination, CT of neck, chest, abdomen and pelvis, full blood count, serum lactate dehydrogenase, and electrophoresis, bone marrow trephination and additional biochemical analysis or endoscopic gastro-intestinal imaging depending on the case.

\section{Statistical methods}

For statistical purposes patients with indolent histological types were grouped together. These included the MALT, follicular, chronic lymphocytic (CLL), lymphoplasmacytic, acute lymphoblastic (ALL), lymphoblastic lymphomas, plasmcytomas, and reactive lymphoid hyperplasia (RLH). T-cell and NK/T-cell lesions, diffuse large B-cell lymphoma (DLBCL) and mantle cell lesions were grouped into the aggressive category. The patient's findings on CT were compared depending on the histologic type using the chi-square test to compare proportions between groups (SPSS software, version 11.0.2; SPSS Inc., Chicago, IL).

\section{Results}

One hundred and five patients, with a mean age at presentation of 61 years (range 11-90 years), were seen during the period of the study. The gender distribution in this cohort was uniform with 52 females and 53 males. There was equal presentation of primary disease limited to the ocular adnexae $v s$ having systemic involvement (53 cases primary/52 cases systemic).

The orbit was the preferred site of involvement (78\%), with the lacrimal gland the most commonly affected (33\%), followed by the extraconal space $(20 \%)$ and the extra ocular muscles (15\%). OALD rarely located to the intraconal space and/or the optic nerve (Table 1).

CT imaging of the orbits was performed in 87 cases. Most of these patients presented with a wellcircumscribed lesion that tended to mould to adjacent tissues, of greater density than brain (Figure 1a and b). In

Table 1 Anatomical site of OALD involvement

\begin{tabular}{lc}
\hline Anatomical site & Frequency and (\%) \\
\hline Orbit & $82(78)$ \\
EOM & $15(15)$ \\
Diffuse & $6(6)$ \\
Intraconal & $2(2)$ \\
Optic nerve & $2(2)$ \\
Extraconal & $21(20)$ \\
Conjunctiva & \\
Lacrimal sac & $9(8.5)$ \\
Eyelid & $9(8.5)$ \\
\hline
\end{tabular}
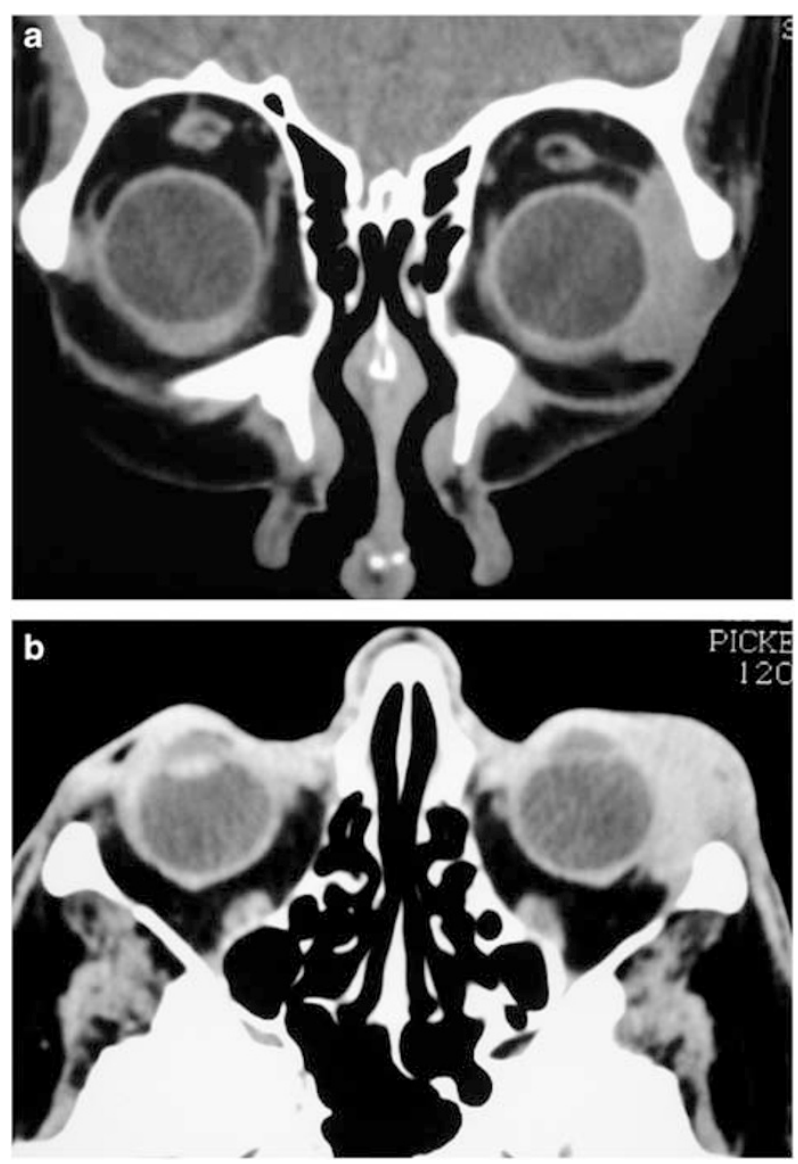

Figure 1 (a, b) Axial and coronal orbital CT scan showing a classical appearance of an indolent OALD in a patient with follicular lymphoma, presenting with an extraconal, homogeneous, well-defined, noncalcified lesion that moulds to the left globe, without producing ocular indentation, bone destruction or invasion into neighbouring tissues. The mass has greater density than the brain. 
Table 2 CT-scan features of OALD

\begin{tabular}{|c|c|c|}
\hline CT features & No of cases & $\%$ \\
\hline \multicolumn{3}{|c|}{ Circumscription } \\
\hline Well & 47 & 54 \\
\hline Moderate & 18 & 21 \\
\hline Poor & 15 & 17 \\
\hline NA & 7 & 8 \\
\hline \multicolumn{3}{|c|}{ Density in relation to the brain } \\
\hline Greater & 65 & 75 \\
\hline Equal & 13 & 15 \\
\hline Less & 0 & 0 \\
\hline NA & 9 & 10 \\
\hline \multicolumn{3}{|l|}{ Enhancement } \\
\hline Marked & 3 & 3 \\
\hline Moderate & 43 & 50 \\
\hline Minimum & 23 & 26 \\
\hline NA & 18 & 21 \\
\hline \multicolumn{3}{|l|}{ Moulding } \\
\hline Present & 63 & 72 \\
\hline Absent & 24 & 28 \\
\hline \multicolumn{3}{|l|}{ Calcification } \\
\hline Present & 5 & 6 \\
\hline Absent & 83 & 94 \\
\hline \multicolumn{3}{|l|}{ Bone changes } \\
\hline Present & 8 & 9 \\
\hline Absent & 79 & 91 \\
\hline \multicolumn{3}{|c|}{ Tissue invasion } \\
\hline Present & 22 & 25 \\
\hline Absent & 65 & 75 \\
\hline
\end{tabular}

Percentages calculate base on a total of 87 cases.

NA represents those cases in which the information was not available.

half of the cases it showed moderate enhancement with contrast media. Calcification and bone destruction were rare and $25 \%$ showed invasion into neighbouring tissues (Table 2) (Figures 2a and b, 3). The aggressive histologic type tended to destroy adjacent bony structures, while moulding was a feature commonly present in the indolent type $(P<0.005)$.

MRI was performed in 24 patients, and tended to present intermediate signal intensity on T1 and T2 and moderate enhancement with gadolinium (Table 3)(Figure $4 a-c)$. Nine patients did not have either CT or MRI studies. These cases had discrete conjunctival, superficial eyelid, or lacrimal sac involvement found only during surgery.

Gallium scanning was performed in 12 cases, of whom seven presented with secondary systemic involvement (Figure 5). At staging, the sensitivity of gallium imaging to detect ocular adnexal disease was $25 \%$ (3/12 cases) and $57 \%$ for the detection of systemic involvement
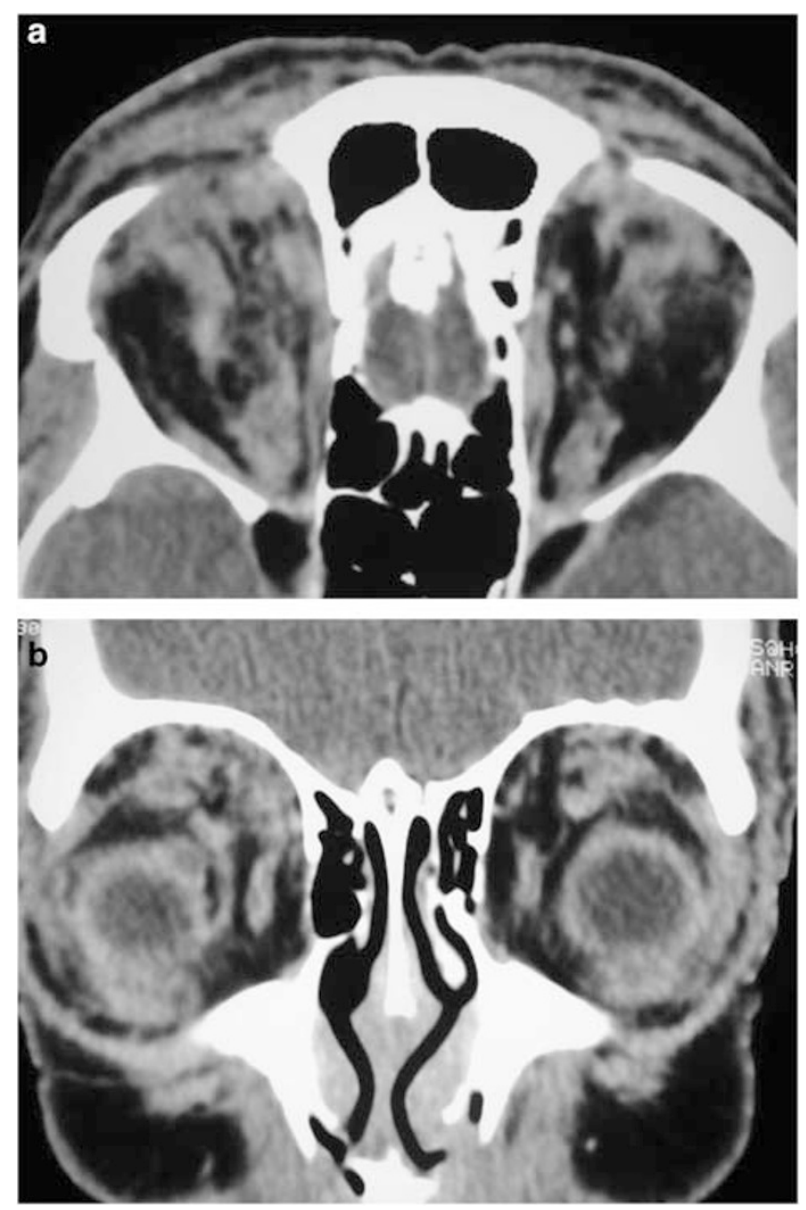

Figure 2 (a, b) Axial and coronal orbital CT scan showing an atypical OALD presentation in a patient with MALT lymphoma, showing a bilateral intra and extraconal infiltrative patchy pattern.

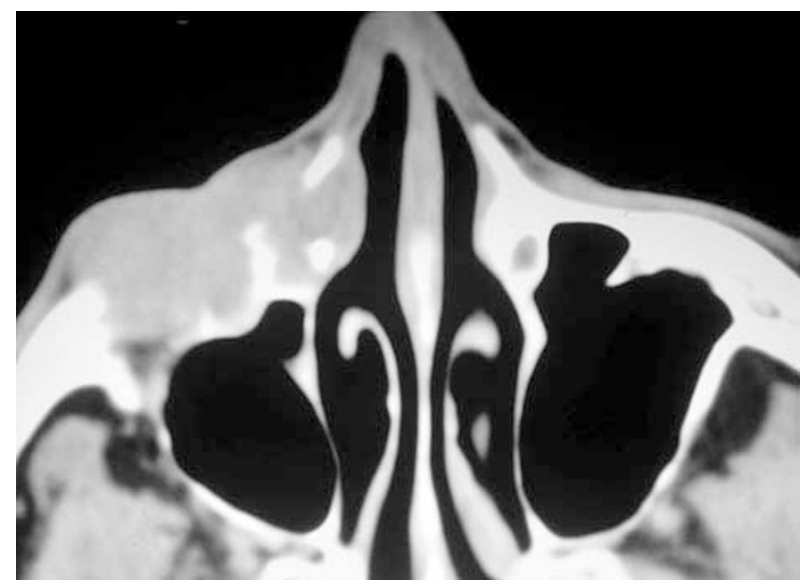

Figure 3 Axial head and orbit CT scan presenting bone destruction in a case of 74-year-old male patient with DLBCL affecting his right lacrimal drainage apparatus.

(4/7 cases). In none of these cases did gallium scanning provide additional information to $\mathrm{CT}$, having no impact on patient management. 
Table 3 MRI-scan features of OALD

\begin{tabular}{lcccr}
\hline MRI parameter & Hypointense $\mathrm{N}(\%)$ & Isointense $\mathrm{N}(\%)$ & Hyperintense $\mathrm{N}(\%)$ & N.A. \\
\hline T1 weighted & $1(4)$ & $18(75)$ & $0(0)$ & $5(21)$ \\
T2 weighted & $0(0)$ & $9(38)$ & $4(17)$ & $11(45)$ \\
Enhancement & Nil & Moderate & Marked & \\
T1FS GD & $2(8)$ & $14(58)$ & $6(24)$ & $2(10)$ \\
\hline
\end{tabular}

Intensity is defined in relation to extra ocular muscles.

$N=$ number of cases; $\%=$ percentage based on a total of $24 ;$ N.A. = data not available; FS GD = Fat suppression with gadolinium.
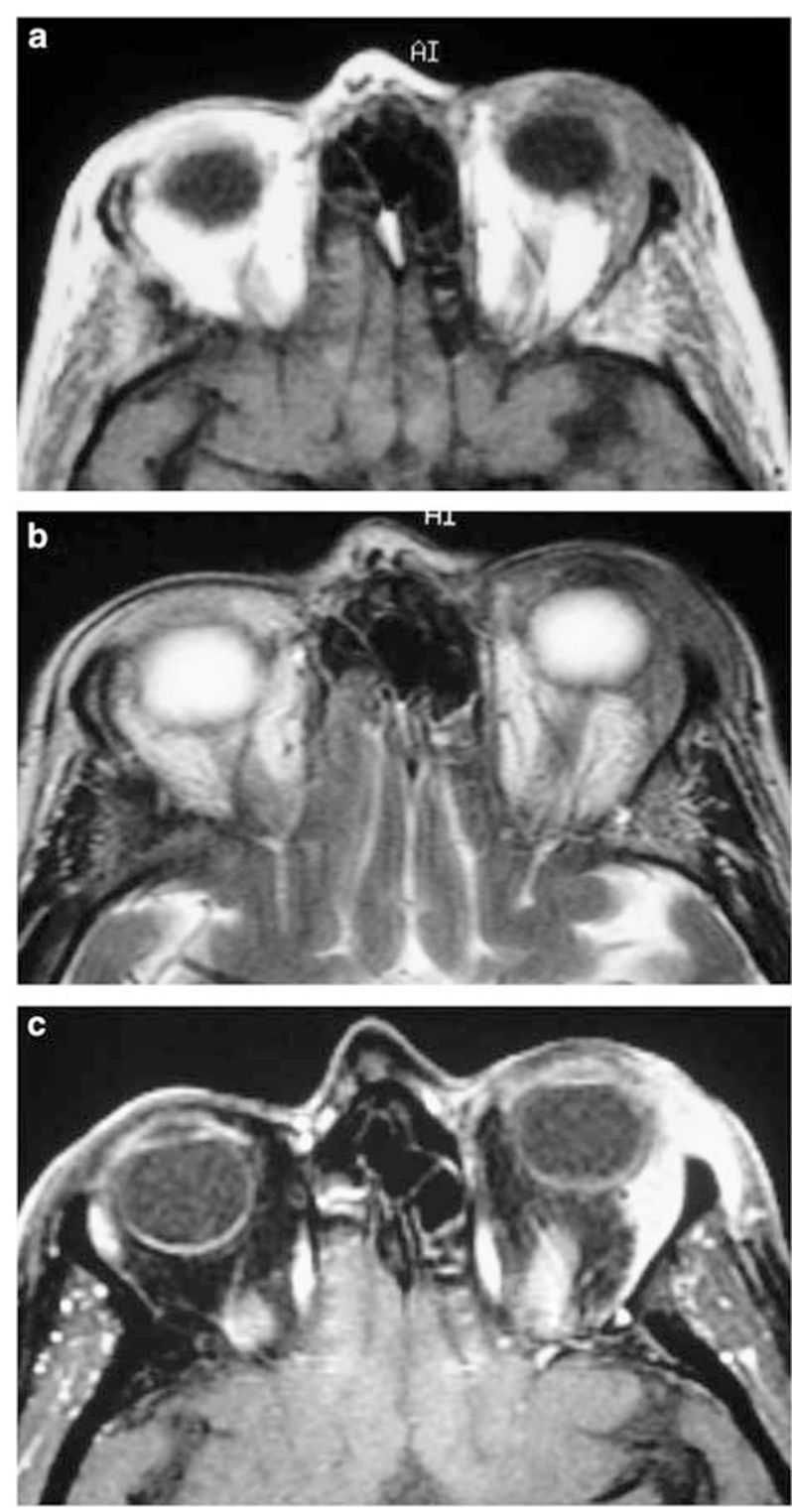

Figure $4 \quad(a-c)$ Axial MRI images of a 74-year-old male patient with DLBCL, presenting with right dacryocystitis and intermittent swelling of the parotid gland. The images show a welldefined mass moulding to the left globe in the anterior orbit, presenting intermediate signal intensity on $\mathrm{T} 1$ and $\mathrm{T} 2$ sequences and moderate enhancement with gadolinium.

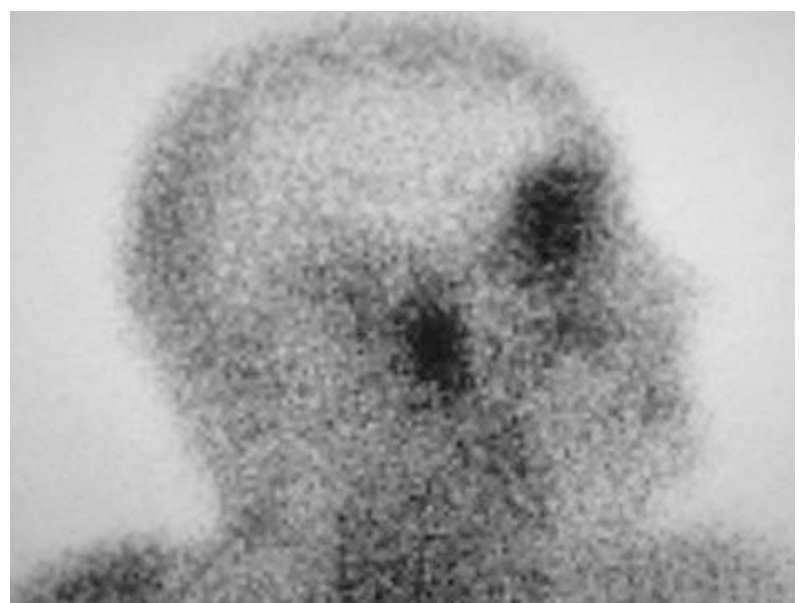

Figure 5 Sagittal head and neck view of gallium scanning in the same patient as Figure 4, showing increased uptake in the right lacrimal and parotid glands.

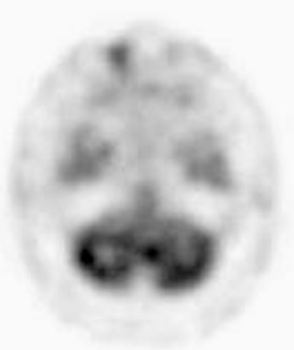

Figure 6 Axial black and white PET showing an increase uptake in the right orbit in a 65-year-old male patient presenting a low-grade B-cell lymphoma located as an orbital mass above his medial canthal tendon.

Positron emission tomography was performed in fourteen patients at staging (Figure 6). Seven cases were primary orbital lymphomas and from the remaining seven, six presented with the systemic disease simultaneously to the ocular adnexal involvement. In this last group with orbital and systemic lymphomatous 
involvement, FDG-PET found distant disease in six, and five of them $(71 \%)$ were upstaged, changing the clinical management. FDG-PET sensitivity in detecting distant disease was $86 \%$. CT of the neck, chest, abdomen, and pelvis showed abnormal findings in five of seven cases, presenting a sensitivity of $72 \%$. FDG-PET provided evidence of tumor activity in borderline areas detected on CT scan in two cases (Follicular Lymphoma $=1$, MALT $=1$ ), guided additional imaging studies in one case (MALT), and detected disease not found with traditional imaging in another two cases (Anaplastic Large Cell Lymphomas). Orbital lesions were demonstrated in 6/14 patients, giving FDG PET a sensitivity of $42 \%$ in detecting orbital lymphoma. Orbital lesions were demonstrated on CT scan in eleven cases, giving a sensitivity of $79 \%$ in detecting orbital lymphoma, a value significantly higher compared to FDG PET.

\section{Discussion}

Early reports of the imaging features of OALD have given rise to classic descriptions which are still current today. ${ }^{1-6}$ Yeo et al studied 26 patients and found that lesions moulded or plastered themselves to pre-existing orbital structures, such as the globe, extraocular muscles, lacrimal gland, or bony orbital walls, without eroding bone or enlarging the orbit. Where lymphoid tumours abutted orbital fat they adopted a streaky profile, presumably due to irregular infiltration reflecting involvement of microfascial structural elements. ${ }^{1}$ Henderson described homogenous tumours of relatively high density with a soft putty-like appearance that showed mild contrast enhancement. ${ }^{12}$ Shields described oblong tumours, oval in shape that often followed the fascial planes of the orbit with a pancake contour. ${ }^{13}$ The difficulty in distinguishing between benign and malignant lymphoid proliferations and between inflammatory and lymphoproliferative lesions has also been stressed. ${ }^{4-6}$ We also found that CT scans most commonly demonstrated lesions that were homogenous, well circumscribed, of greater than brain density, moderately enhancing and moulded to adjacent orbital structures, as per these previous classic descriptions. (Figure 1a and b) There was a statistically significant association between indolent histology and the CT appearance of moulding. Nonetheless, we also saw atypical lesions that showed an infiltrative pattern, were inhomogeneous, or had calcification or bone changes (Figures 2a and b, 3). These atypical imaging appearances occurred across all histological groups but were more highly represented by the diffuse large B-cell (DLBCL) and T-cell lymphomas, with a statistically significant association between bone destruction and aggressive histology. Interestingly, the three mantle cell tumours in our series, despite their aggressive behaviour, did not show tissue invasion or bone destruction but showed the moulding characteristics associated with indolent lesions. Similar to others, we were unable to distinguish reactive lesions from true lymphoma. ${ }^{1,6}$

MRI studies have also been reported, with some authors stating that T2-weighted images were helpful because of lesion hyperintensity. ${ }^{14,15}$ Other authors found variable lesion intensity on T2 images. ${ }^{6}$ We found that both T1-and T2-weighted images were isointense to extraocular muscle and showed moderate enhancement with gadolinium in the majority of cases., ${ }^{5,6}$ (Table 3) (Figure $4 \mathrm{a}-\mathrm{c}$ ) These findings were nonspecific and similar to those found by others. 5,7

We consider that both CT and MRI provide useful information about disease in the ocular adnexea but that CT offers some advantages in atypical cases, which may show bone changes. MRI provides complementary information and demonstrates extension into adjacent structures such as the CNS and sinuses very well.

Systemic imaging screening with Gallium $\left({ }^{67} \mathrm{Ga}\right)$ and FDG-PET were useful as noninvasive methods for establishing the stage of OALD. FDG-PET is currently our preferred method for systemic evaluation, with greater sensitivity than either Gallium or CT. Gallium scanning has been largely superseded by FDG-PET. The mechanism of intracellular accumulation of ${ }^{67} \mathrm{Ga}$ in lymphoproliferative disease is still a controversy, possibly due to preferential uptake of transferrin by malignant cells, altered plasma membrane function and/or slow clearance from lysosyme-like granules in tumour cells. ${ }^{16-21}$ The cooperative studies in the 1970s reported patient and site sensitivity of approximately $65 \%$ for the detection of non-Hodkin's lymphoma. ${ }^{22,23}$ Improved technology and the use of single photon emission computed tomography (SPECT) increase the accuracy of gallium scanning at initial staging from $78 \%$ with planar imaging to $85 \%$ with the use of SPECT. ${ }^{24-27}$ Unfortunately, in our study, Gallium imaging found disease only in $50 \%$ of the cases, providing no additional information to CT/MRI and did not change clinical management in any case. Gallium scanning has been gradually replaced in our management by FDG-PET since 2002.

FDG-PET uptake by malignant cells is also an expression of altered metabolism occurring during malignant transformation, in which glycolysis becomes the main metabolic pathway. ${ }^{28}$ With increased numbers of glucose transporters on the tumour cell surface and the enhanced activity of some glycolytic enzymes, there is an increased uptake by malignant cells as compared with normal tissues. Inside the cell, FDG is converted in FDG-6-phosphate, which is not a suitable substrate for 
further glycolysis, and is dephosphorylated at a decreased rate. FDG is, therefore, trapped intracellularly in the viable tumour. The intracellular accumulation of FDG reflects the glycolytic metabolic rate in malignant cells and is useful for imaging cancerous tissues. ${ }^{28,29}$ High avidity of FDG has been described for most types of lymphoma. ${ }^{30-35}$ In our study, FDG-PET presented a higher sensitivity in detecting systemic disease $(86 \%)$ in comparison to gallium scanning (57\%) and CT-scan imaging (72\%). ${ }^{36}$ The sensitivity to detect disease affecting the ocular adnexae was higher than gallium scanning (42 vs 25\%), but significantly lower than CTscan (42 vs 79\%). FDG-PET changed the management in $71 \%$ of the secondary OALD patients, detecting viable sites of active systemic disease, providing whole body screening, and guiding specific diagnostic studies (directing MRI-CT, expert assessment, bone marrow biopsy, etc) in selected cases. We consider that its ability to find systemic extra-nodal lymphomatous sites, not detected with traditional imaging, offers valuable information to refine and guide the management of OALD patients. ${ }^{36}$ However, this test also has limitations due to multiple factors, such as: the relatively small tumour volume of adnexal lesions, the large amount of background physiological activity in the orbits from the extra-ocular muscles and the proximity to the intense physiological uptake from the brain. ${ }^{36,37}$ The development of simultaneous PET-CT scanning provides combined images of morphology and function in the same study, providing useful information for the optimal management in these patients. ${ }^{38}$

Our approach for the imaging in patients with OALD is to request an axial and coronal head and orbit CT-scan with contrast prior to the biopsy of any case in which a lymphoproliferative disease is suspected, in an attempt to define the location, extension, tissue invasion, bone changes and intrinsic features of the lesion (homogeneity, moulding, enhancement, etc). MRI may help in a number of situations, such as cases, which present a convex contour in the superior orbit on CT which might be due to lymphoma or due to a subperositeral haematoma. The different signal characteristics of blood breakdown products allow differentiation. CNS and sinus involvement can also be assessed with MRI.

After histopathological confirmation, a systemic workup by an oncologist should ideally include a whole body FDG-PET and CT of the neck-chest-abdomen and pelvis at staging, to detect possible systemic involvement and guide specific additional studies. We follow our patients with a new head and orbit CT-scan or MRI after the treatment is completed, usually $4-6$ months after the diagnosis. Regarding the possibility of local adnexal recurrence, we continue requesting orbital CT-scans 6 monthly for the first year, independent on the histological type. The imaging studies are then performed yearly for 2 years. Following that images are requested if there is any clinical suggestion of local recurrence. If a relapse is suspected at any stage, CT or MRI and FDG-PET is requested and further oncological staging is performed as previously described. As a result of the known incidence of late local and systemic recurrence and mortality, we believe that these patients should be followed for life, in conjunction with the treating oncologist and the family practitioner. ${ }^{11,39}$ When CT-PET becomes more widely available, this may become the preferred technique, considering this combines functional and anatomical information simultaneously.

\section{References}

1 Yeo JH, Jakobiec FA, Abbott GF, Trokel SL. Combined clinical and computed tomographic diagnosis of orbital lymphoid tumors. Am J Ophthalmol 1982; 94(2): 235-245.

2 Weber AL, Dallow RL, Oot RF. CT evaluation of lymphoproliferative disease of the orbit in fifty patients. In: Greitz T (ed). Thirteenth symposium Neuroradiologicum. Stockholm, June 23-28, 1986. Stockholm: Acta Radiol Suppl; 1987.

3 Flanders AE, Espinosa GA, Markiewicz DA, Howell DD. Orbital lymphoma. Role of CT and MRI. Radiol Clin North Am 1987; 25(3): 601-613.

4 Westacott S, Garner A, Moseley IF, Wright JE. Orbital lymphoma $v$ reactive lymphoid hyperplasia: an analysis of the use of computed tomography in differential diagnosis. Br J Ophthalmol 1991; 75(12): 722-725.

5 Chisin R, Weber AL. Imaging of lymphoma manifestations in the extracranial head and neck region. Leuk Lymphoma 1994; 12(3-4): 177-189.

6 Polito E, Galieni P, Leccisotti A. Clinical and radiological presentation of 95 orbital lymphoid tumors. Graefes Arch Clin Exp Ophthalmol 1996; 234(8): 504-509.

7 De Potter P, Dolinskas C, Shields CL, Shields JA. Lymphoproliferative and histiocytic disorders. In: De Potter P, Shields JA, Shields CL (eds). MRI of the eye and orbit. J.B. Lippincott: Philadelphia, 1995, pp 245-247.

8 Chan JKC, Banks PM, Cleary ML et al. A proposal for classification of lymphoid neoplasms (by the International Lymphoma Study Group). Histopathology 1994; 25: 517-536.

9 Chan JK, Banks PM, Cleary ML et al. A revised EuropeanAmerical classification of lymphoid neoplasms by the International Lymphoma Study Group. A summary version. Am J Clin Pathol 1995; 103: 543-560.

10 Jaffe ES, Harris NL, Diebold J, Muller-Hermelink H-K. World Health Organisation classification of neoplastic diseases of the hematopoietic and lymphoid tissues. Am J Clin Pathol 1999; 111(Suppl): S8-S12.

11 Sullivan TJ, Whitehead K, Williamson R, Grimes D, Schlect $\mathrm{D}$, Brown I et al. Lymphoproliferative disease of the ocular adnexae: a clinical and pathological study with statistical analysis of 69 patients. Ophthal Plast Reconstr Surg 2005; 21: 177-188.

12 Henderson JW. Hemotopoietic tumors. In: Henderson JW (ed). Orbital Tumors, 3rd ed. Raven Press: New York, 1994, pp 279-307. 
13 Shileds JA, Saunders WB. Lymphoid tumors and leukemias. In: Shileds JA, Saunders WB (eds). Diagnosis and management of orbital tumors. J.B. Lippincott: Philadelphia, 1989, pp 316-340.

14 Bilanjuk LT, Zimmerman RA, Newton TH. Magnetic resonance imaging. Orbital pathology. In: Newton TH, Bilaniuk LT (eds). Radiology of the eye and orbit. Raven Press: New York, 1990, pp 5.1-5.84.

15 Flanders AE, Espinosa GA, Markiewicz DA, Howell DD. Orbital lymphoma: role of CT and MRI. Radiol Clin North Am 1987; 25: 601-614.

16 Gunasekera SW, King LJ, Lavender PJ. The behaviour of tracer gallium- 67 towards serum proteins. Clin Chim Acta 1972; 2: 401-406.

17 Wong H, Terner UK, English D, Noujaim AA, Lentle BC, Hill JR. The role of transferrin in the in vivo uptake of gallium-67 in a canine tumor. Int J Nucl Med Biol 1980; 7: 9-16.

18 Anghileri LJ. Cell membrane permeability and tumor scanning agents: facts and possibilities. J Nucl Med Allied Sci 1978; 22: 101-103.

19 Muranka A, Ito $\mathrm{Y}$, Hashimoto $\mathrm{M}$ et al. Uptake and excretion of 67-Ga-citrate in malignant yumors and normal cells. Eur J Nucl Med 1980; 5: 31-37.

20 Brown DH, Swartzendruber DC, Carlton JE, Byrd BL. The isolation and characterization of gallium-binding granules from soft tissue tumors. Cancer Res 1973; 33: 2063-2067.

21 Hayes RL, Carlton JE. A study of macromolecular binding of 67-Ga-citrate in normal and malignant tissues. Cancer Res 1973; 33: 3265-3272.

22 Johnson GS, Go MF, Benua RS et al. Gallium-67-citrate imaging in Hodkin's disease:final report of coorperative group. J Nucl Med 1977; 18: 692-698.

23 Andrews GA, Hubner KF, Greenlaw RH. Ga-67 citrate imaging in malignant lymphoma. J Nucl Med 1978; 19: 1013-1019.

24 Bekerman C, Szidon JP, Pinsky S. The role of gallium-67 in the clinical evaluation of sarcoidosis. Semin Roentgenol 1985, 20: 400-409.

25 Anderson KC, Leonard RC, Canellos GP, Skarin A, Kaplan WD. High-dose gallium imaging in lymphoma. AM J Med 1983; 75: 327-331.

26 Front D, Israel O, Epelbaum R, Ben Haim S, Sapir ES, Jerushalmi J et al. Ga-67 SPECT before and after treatment of lymphoma. Radiology 1990; 175: 515-519.
27 Tumeh SS, Rosenthal DS, Kaplan WD, English RJ, Holman BL. Lymphoma: evaluation with Ga-67 SPECT. Radiology 1987; 164: 111-114.

28 Weber G. Biochemical strategy of cancer cells and the design of chemotherapy. GHA Clowes memorial lecture. Cancer 1983; Res 43: 3466-3492.

29 Bar-Shalom R, Valdivia AY, Balufox MD. PET imaging in oncology. Semin Nucl Med 2000; 30: 150-185.

30 Paul R. Comparison of fluorine-18deoxyglucose and gallium-67 citrate imaging for detection of lymphoma. I Nucl Med 1987; 28: 288-292.

31 Okada J, Yoshikawa K, Imazeki K et al. The use of FDG-PET in the detection and management of malignant lymphoma: correlation of uptake with prognosis. J Nucl Med 1991; 32: 686-691.

32 La-pela M, Leskinen S, Minn HRI et al. Increase glucose metabolism in untreated non-Hodgkin's lymphoma: a study with positron emission tomography and fluorine18deoxyglucose. Blood 1995; 86: 3522-3527.

33 Leskinen-Kallio S, Ruotsalainen U, Nagren K et al. Uptake of carbon-11-methionine and fluorodeoxyglucose in nonHodgkin's lymphoma: a PET study. J Nucl Med 1991; 32 1211-1218.

34 Rodriguez M, Rhen S, Ahlstrom $\mathrm{H}$ et al. Predicting malignancy grade with PET in non-Hodgkin's lymphoma. J Nucl Med 1995; 36: 1790-1796.

35 Jerusalem G, Warland V, Majjar F et al. Whole body 18FFDG-PET for the evaluation of patients with Hodgkin's disease and non-Hodgkin's lymphoma. Nucl Med Commun 1999; 20: 13-20.

36 Valenzuela AA, Allen C, Grimes D, Wong D, Sullivan TJ. Positron emission tomography in the detection and staging of ocular adnexal lymphoproliferative disease. Ophthalmology 2006, doi:10.1016/j.ophtha.2006.05.059.

37 von Schulthess GK. Clinical Molecular Anatomic Imaging PET, PET/CT and SPECT/CT. Lippincott Williams \& Wilkins: Sydney, 2003.

38 Hicks RJ, MacManus MP, Seymour JF. Initial staging of lymphoma with positron emission tomography and computed tomography. Sem Nucl Med 2005; 35: 165-175.

39 Jenkins C, Rose GE, Bunce C, Cree I, Norton A, Plowman $\mathrm{PN}$ et al. Clinical features associated with survival of patients with lymphoma of the ocular adnexa. Eye 2003; 17: 809-820. 